DOI: 10.12957/demetra.2016.19508

\title{
Hotelaria marítima: segmento de atuação do nutricionista na área de alimentação coletiva
}

Maritime hotel company: nutritionist's operating segment in food service

Aline Gomes de Mello'

Gabriella Barcellos Almeida²

Lorena Gonçalves de Oliveira ${ }^{3}$

Luciléia Granhen Tavares Colares'

Mariana Fernandes Brito de Oliveira ${ }^{3}$

' Universidade Federal do Rio de Janeiro, Departamento de Nutrição e Dietética, Setor de Administração de Serviços de Alimentação, Instituto de Nutrição Josué de Castro. Rio de Janeiro-RJ, Brasil.

${ }^{2}$ Cis Brasil Ltda. Macaé-RJ, Brasil.

${ }^{3}$ Universidade Federal do Rio de Janeiro, Núcleo Alimentação Coletiva, Curso de Nutrição. Campus Macaé, Macaé-RJ, Brasil.

Correspondência / Correspondence

Aline Gomes de Mello

alinemello@nutricao.ufri.br

\section{Resumo}

Este estudo visou descrever as atividades relacionadas a alimentação e nutrição em empresa de hotelaria marítima (EHM). Tratou-se de um estudo de caso realizado por observação sistemática e análise documental, para identificação das atividades e dos profissionais envolvidos no processo produtivo de refeições, apoiado em pesquisa exploratória de campo. As atividades relacionadas à alimentação e nutrição ocorriam em terra (onshore) - na base de apoio; e em alto mar (offshore) - nas plataformas. O planejamento de cardápio, aquisição, recebimento e armazenamento de materiais, assim como a montagem e embarque dos contêineres com material de rancho e demais materiais para as plataformas era feito onshore; e o recebimento e armazenamento dos materiais, produção e distribuição de refeições, offshore. O transporte dos contêineres para plataforma poderia ocorrer em até 48 horas, dependendo da localização e das condições marítimas, logo o controle do tempo e temperatura do material de rancho (alimentar) era determinante para manter a qualidade e sanidade do mesmo. Os nutricionistas realizavam as atividades obrigatórias e complementares previstas para a atuação na área de alimentação coletiva. A inspeção da qualidade do material de rancho recebido na plataforma era de responsabilidade dos profissionais de saúde, dentre eles, o nutricionista. Conclui-se que o processo produtivo de refeições é semelhante ao conduzido por diversas unidades de alimentação e nutrição, porém, como na EHM algumas etapas ocorrem onshore, e outras offshore, faz-se necessário adotar medidas rigorosas de controle quantitativo e qualitativo, pois falhas de planejamento podem resultar em custos adicionais para a empresa.

Palavras-chave: Serviços de Alimentação. Fluxo de Trabalho. Refeições. Armazenamento de Alimentos. 


\section{Abstract}

This study aimed to describe the activities related to food and nutrition in maritime hotel company. A case study was conducted in maritime hotel company, supported by exploratory research. To identify the activities and professionals involved in meal production process, systematic observation and document research were carried out. Activities related to food and nutrition could occur onshore - in the support base; and offshore - in the oil platforms. Menu planning, purchasing and storage of foodstuffs, assembly and shipment of these materials to platforms were performed onshore, while receiving, storage of material, production and distribution of meals were performed offshore. Transport the foodstuffs to oil platform can take up to 48 hours, depending on location and sea conditions, so the control of time and temperature was crucial to maintain the quality of the food. In maritime hotel company, nutritionists developed the mandatory and complementary activities prescribed for work in the food service. Health professionals, and among them the nutritionist, were responsible for inspecting foodstuffs received in the oil platform and also check the sanitary quality of food for preparation of meals. It is concluded that the production of meals is similar to other food services, however, in the maritime hotel company some steps take place onshore, and others offshore. Rigorous quantitative and qualitative controls are required, since failures in controls may result in additional costs for the company.

Key words: Food Services. Workflow. Meals. Food Storange.

\section{Introdução}

A alimentação coletiva é uma das áreas de atuação do nutricionista, segundo a Resolução do Conselho Federal de Nutrição (CFN) 380/2005. ${ }^{1}$ As atividades podem ser realizadas em unidades de alimentação e nutrição (UAN), tais como: empresas fornecedoras de serviços de alimentação coletiva, restaurantes comerciais, comissarias, cozinhas dos estabelecimentos assistenciais de saúde, hotéis, dentre outros locais. ${ }^{1}$

A hotelaria é um segmento em expansão, em que há a produção de bens e serviços com vistas a hospedagem, alimentação e segurança do trabalho. Todas essas atividades estão voltadas para o bem receber e para o atendimento das diferentes necessidades dos hóspedes e do próprio negócio.,3 
Até pouco tempo, este segmento se referiu tanto à hospedagem em terra (hotelaria onshore) quanto às atividades náuticas caracterizadas pela utilização de embarcações para a movimentação de passageiros, com fins meramente turísticos. A exploração do petróleo em alto mar (offshore), no Brasil, teve início na década de 1990, ${ }^{4}$ havendo o desenvolvimento de outra modalidade de hotelaria, a marítima, relativa ao atendimento às necessidades dos trabalhadores que permanecem em alto mar desenvolvendo atividades de extração de petróleo. ${ }^{3}$ Portanto, a empresa de hotelaria marítima visa oferecer aos trabalhadores que atuam em unidades de extração de petróleo (plataformas e navios) hospedagem, entretenimento, segurança e alimentação. ${ }^{5}$

As empresas de hotelaria marítima, recentemente, têm sido campo de trabalho para os nutricionistas que desenvolvem suas atividades profissionais da área de alimentação coletiva, tanto na base de apoio e logística - localizada em terra (onshore), como nas plataformas de petróleo localizadas em alto mar (offshore). Pesquisas referentes a este segmento ainda são escassas e, em sua maioria, abordam as questões relativas a acidentes de trabalho ${ }^{6}$ e condições de trabalho do enfermeiro, ${ }^{7,8}$ que pelas Normas da Autoridade Marítima para Aquaviários (NORMAM) nํ13/2003, ${ }^{9}$ é o profissional responsável, além de outras atribuições, por atividades relativas a alimentação e nutrição, como: acompanhar a entrada do material de rancho a bordo e examinar diariamente os gêneros que saem dos paióis e câmaras frigoríficas para o preparo das refeições. Dessa forma, este estudo visa descrever as atividades relacionadas a alimentação e nutrição em empresas de hotelaria marítima.

\section{Materiais e Métodos}

Tratou-se de estudo de caso realizado por observação sistemática ${ }^{10,11}$ e análise documental, apoiado em pesquisa exploratória de campo, ${ }^{12,13}$ conduzido durante o primeiro semestre de 2014 em uma empresa multinacional de hotelaria marítima, cuja base está localizada nos municípios de Macaé-RJ e de Aracaju-SE. O estudo foi autorizado pela empresa de hotelaria marítima.

Durante a observação sistemática, foi utilizado um roteiro para identificar as atividades referentes ao processo produtivo de refeições e a atuação do nutricionista neste segmento, sendo coletadas as seguintes informações: processo de aquisição, recebimento e armazenamento de materiais, transporte de materiais para as plataformas de petróleo e produção e distribuição das refeições nas plataformas. Além disso, foi feita consulta ao manual de boas práticas da empresa.

a Material de rancho: gêneros alimentícios e descartáveis a serem utilizados por um determinado período de tempo na produção e distribuição de refeições para coletividades em hotelaria marítima e UAN militares. 
Realizou-se análise documental para identificação das atividades e dos profissionais envolvidos, sendo consultado o documento denominado: "Responsabilidade e autoridade". Nesta etapa, foram coletadas as seguintes informações: profissionais envolvidos no processo produtivo de refeições, local de atuação (onshore ou offshore), jornada e período de trabalho, média salarial dos nutricionistas e atividades desenvolvidas. Para obter informações sobre o número de plataformas atendidas pela empresa, número de refeições servidas diariamente nas plataformas e a composição do cardápio, foram consultados os contratos de prestação de serviços.

Pretendeu-se, com esse recorte, não generalizar, mas aprofundar algumas questões que poderão ser estudadas em outras empresas de hotelaria marítima, uma vez que há escassez de conhecimento acumulado e sistematizado abordando a temática.

\section{Resultados e Discussão}

\section{O ambiente de trabalho em empresa de hotelaria marítima}

A empresa de hotelaria marítima, objeto deste estudo, presta serviços terceirizados relacionados com a limpeza e organização de toda área do casario (área habitacional da plataforma ou navio em que estão localizadas as áreas de lazer, alimentação e os camarotes (nome dado aos quartos dentro das plataformas), salas de controle, enfermaria, serviço de lavanderia, assim como recebimento, armazenamento de materiais, produção e distribuição de refeições para 23 plataformas de petróleo (16 nacionais e 7 internacionais).

A empresa de hotelaria marítima realizava atividades em terra (onshore), na base de apoio e logística, localizada na cidade de Macaé-RJ e em alto mar (offshore), nas unidades de extração de petróleo (plataformas) localizadas na Bacia de Campos-RJ.

A empresa possuía um quadro de 1.140 colaboradores, sendo o recrutamento, a seleção e o treinamento realizados na base de apoio e logística. As plataformas contavam com trabalhadores ocupando os cargos: taifeiro, responsável pela limpeza e organização do casario e pelos serviços de lavanderia e governança; recepcionista; rádio operador; técnico de manutenção; técnico de segurança do trabalho; nutricionista; chefe de cozinha; cozinheiro; padeiro; auxiliar de cozinha; saladeiro; saloneiro (garçom) e paioleiro (estoquista). A quantidade de trabalhadores nas unidades localizadas offshore depende do seu porte e automação, mas há limitação do número de pessoas embarcadas, a fim de viabilizar o abandono da unidade, em situação de emergência. ${ }^{14,15}$

Um pré-requisito peculiar deste segmento é a exigência de Curso Básico de Segurança de Plataforma, denominado Salvatagem - que visa capacitar o trabalhador não aquaviário para executar procedimentos de segurança a bordo, e o curso para Escape de Helicóptero Submerso, 
denominado Huet. Sem esses cursos, o trabalhador não está habilitado ao embarque. Atualmente, o Huet é um requisito apenas para embarque nas plataformas estrangeiras. Esses cursos, normalmente, são custeados pelo próprio profissional interessado em atuar no segmento offshore.

A jornada de trabalho na base de apoio e logística era de 44 horas semanais e ocorria de segunda a sexta-feira, das 8 às 18:00h, podendo também ser realizada nos finais de semana. Eram garantidos, portanto, todos os direitos como pagamento de horas extras, quando necessário, e o descanso semanal remunerado.

As unidades de exploração de petróleo (plataformas) funcionavam 24 horas por dia, de forma ininterrupta ${ }^{14,16}$ e os trabalhadores permaneciam 14 dias embarcados e 14 dias descansando em terra, sendo a jornada de trabalho de 12 horas diárias. Quando era necessária a realização de horas extras, estas não poderiam exceder duas horas por dia, conforme descrito na Lei no 5811 , 11 de outubro de $1972 .{ }^{17}$

O período de dias de trabalho embarcado e dias de descanso em terra podem variar conforme o país. No Reino Unido, há alternância de 14 dias de trabalho e 14 dias de descanso; nos Estados Unidos, o período de trabalho/descanso é de 7/7 dias; na Noruega há uma progressão de 14/14 no primeiro ciclo, 14/21 no segundo ciclo e $14 / 28$ no terceiro. ${ }^{18}$ No Brasil, o regime de trabalho dos profissionais que atuam em unidades de exploração de petróleo está amparado pela Lei n⿳o 5811, 11 de outubro de $1972 .{ }^{17}$

Dada a longa permanência dos trabalhadores nas unidades de exploração de petróleo, estas contavam com entretenimento, como: sala de televisão, sala de vídeo, academia, sala de jogos, dentre outros. Em algumas unidades localizadas offshore, o uso de telefone era limitado em tempo e quantidade de ligações por dia já em outras, era liberado de acordo com a função exercida. Algumas plataformas também possuíam internet, porém era necessário o agendamento prévio para utilizá-la e o tempo de acesso também era limitado. Em todas as unidades, existiam quiosques para venda de gêneros de higiene pessoal, cigarros e doces, de acordo com o contrato firmado.

Embora nas unidades de exploração de petróleo fossem disponibilizados entretenimentos, os trabalhadores que atuam nesses ambientes estão expostos a fatores de estresse relacionados a intempéries, excesso de ruído, alta demanda de trabalho e distanciamento das atividades sociais e familiares. ${ }^{19,20}$

O processo de trabalho em UAN, independentemente de sua localização, possui semelhança. Em estudo realizado por Colares e Freitas, ${ }^{21} \mathrm{em}$ restaurante universitário foi observada pressão temporal relacionada a produção e distribuição de refeições, condições inadequadas de trabalho e processos, que afetam potencialmente a saúde mental, devido a aborrecimentos e estresse. Estas condições laborais também podem ser observadas em uma UAN localizada offshore; e ainda, podem estar associadas a peculiaridades do segmento de hotelaria marítima, como riscos de 
desenvolvimento de distúrbios de ritmos biológicos, uma vez que o trabalho é realizado em turnos e há fatores psicossociais desfavoráveis, devido ao regime de confinamento em alto mar e ao estilo de vida imposto aos trabalhadores. ${ }^{22}$

O regime de confinamento (que pode ser definido como limitação de espaço e da possibilidade de ir e vir, associado ao isolamento social e distanciamento da família) ${ }^{23}$ dificulta o relaxamento, pois há uma proximidade entre o trabalho, a alimentação, o lazer, o repouso e o atendimento à saúde. ${ }^{24}$ Pode, ainda, favorecer o consumo de alimentos pouco saudáveis (ultraprocessados), como forma de alívio de estresse. Nessa situação, deve-se também considerar a possibilidade de surgimento de conflitos, uma vez que há convivência de profissionais de diferentes áreas de atuação, culturas e nacionalidades por longo período de tempo.

\section{Atuação do nutricionista em hotelaria marítima}

Na empresa de hotelaria marítima estudada, havia 33 nutricionistas, sendo 90,9\% do gênero feminino, com faixa etária compreendida entre 25 e 45 anos de idade. Na tabela 1, apresentamse as informações sobre a caracterização da atuação do nutricionista em hotelaria marítima. Em relação ao salário, vale ressaltar que os valores acrescidos podem se diferenciar de acordo com o plano de cargos e salários da empresa. 


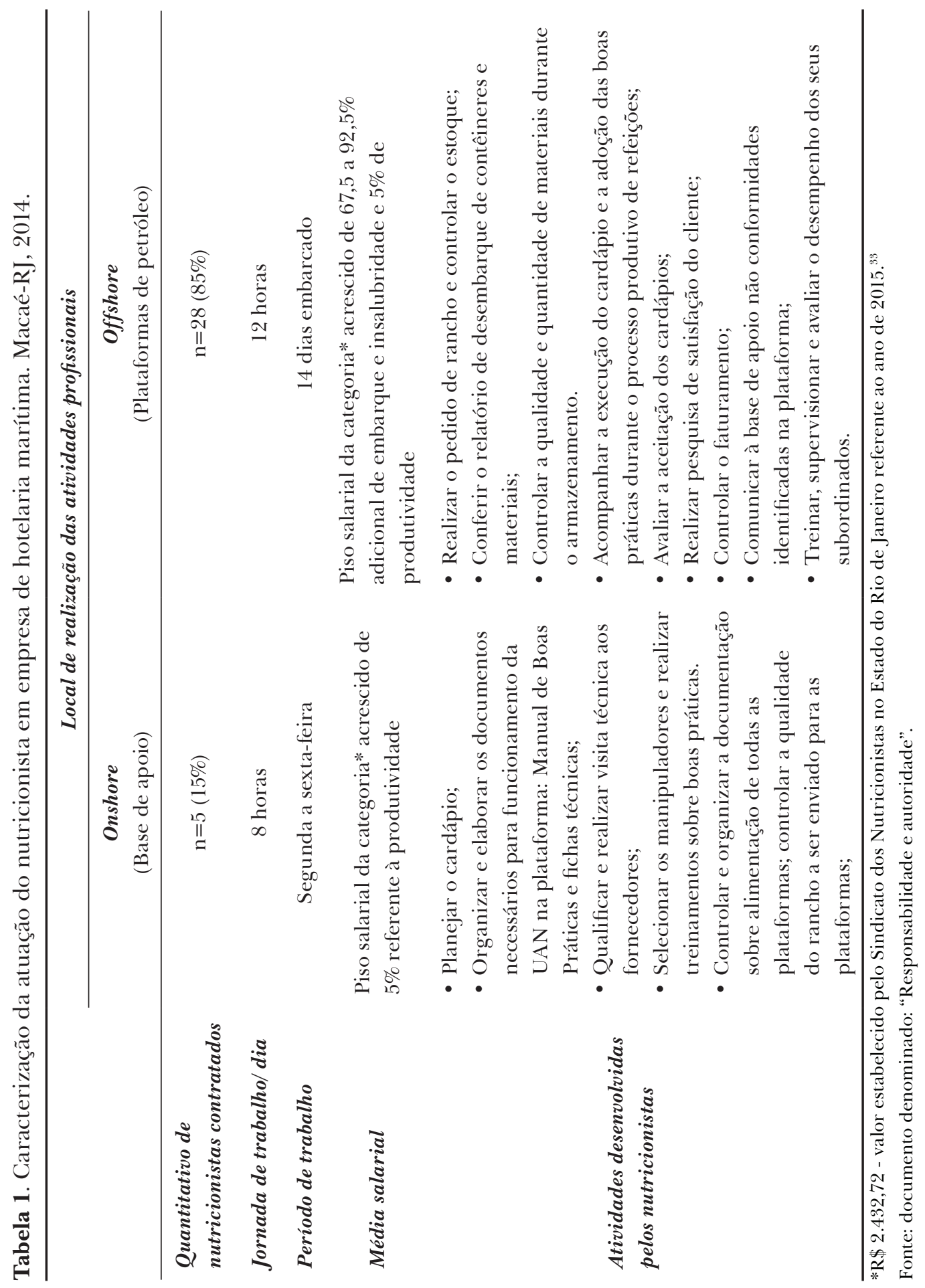


Das 23 plataformas atendidas, nove (39\%) não contavam com nutricionista, pois não era previsto em contrato; no entanto, a Resolução CFN n³80/2005¹ recomenda, no mínimo, um nutricionista por quinzena, por unidade de exploração de petróleo.

Apesar dos riscos existentes e da condição de confinamento vivenciados nas unidades de exploração de petróleo, a motivação para o trabalho embarcado se dá devido ao salário, pois pode haver um acréscimo de até $92 \%$ do piso salarial previsto pelo Sindicato dos Nutricionistas do Estado do Rio de Janeiro (SINERJ), quando comparado aos salários dos nutricionistas que desenvolvem suas atividades em UANs localizadas onshore (tabela 1).

As atividades realizadas pelos nutricionistas da empresa estudada eram semelhantes àquelas desempenhadas nos demais segmentos da área de alimentação coletiva e estão descritas na Resolução CFN no 380/2005, ${ }^{1}$ sendo que algumas atividades consideradas obrigatórias e complementares eram executadas onshore (relacionadas a planejamento do serviço) e outras, offshore (relacionadas a organização, ao comando e controle do processo de produção de refeições), também segundo a tabela 1. Vale ressaltar que os nutricionistas que desempenhavam suas atividades nas plataformas poderiam, ainda, realizar atividades não inerentes a sua profissão, como: controle de serviços de lavanderia, radiotelefonia, recepção e limpeza, caso seja acordado em contrato. No entanto, independentemente do segmento de atuação, o nutricionista é um profissional de saúde e tem a responsabilidade de contribuir para promover, preservar e recuperar a saúde dos indivíduos, visando ao bem-estar individual e da coletividade. ${ }^{1}$

\section{Descrição do processo produtivo de refeições na empresa de hotelaria marítima estudada}

O processo produtivo de refeições nas unidades de exploração de petróleo segue fluxo ordenado, a fim de minimizar os riscos de contaminação, e apresenta as seguintes etapas: planejamento de cardápio, aquisição de materiais, transporte, recebimento e armazenamento de materiais, preparo dos alimentos e distribuição das preparações. ${ }^{25}$ Todo esse processo ocorre em espaços diferenciados, onshore e offshore.

\section{Atividades desenvolvidas onshore}

As atividades de alimentação e nutrição realizadas onshore ocorriam na base de apoio e logística, onde havia o planejamento de cardápio, aquisição, recebimento, armazenamento de materiais, seleção do material de rancho e outros materiais (como de limpeza) para a montagem dos contêineres, além do transporte dos mesmos até o porto e embarque em rebocadores/barcos para as plataformas (figura 1). Na mesma figura, está descrito o fluxograma das atividades de alimentação e nutrição realizadas pela empresa de hotelaria marítima estudada. 


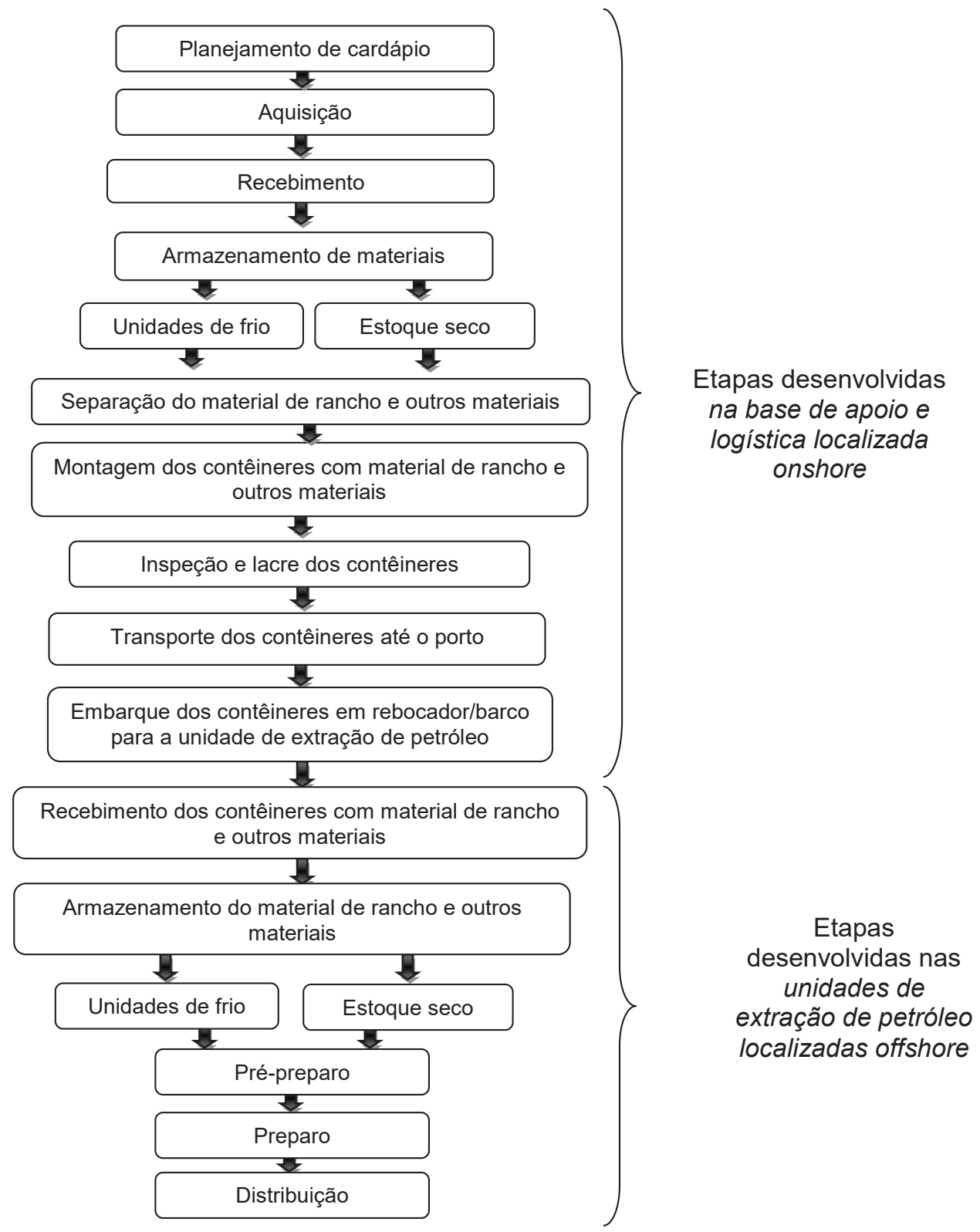

Figura 1. Fluxograma das atividades de alimentação e nutrição realizadas pela empresa de hotelaria marítima estudada. Macaé-RJ, 2014. 
O planejamento do cardápio era realizado de acordo com o contrato firmado entre a contratante e a empresa de hotelaria marítima (contratada), podendo ser elaborado pela nutricionista de planejamento, localizada onshore ou pela contratante.

Na unidade estudada, o cardápio apresentava a seguinte estrutura: quatro saladas de entrada (sendo 1 folhoso, 2 compostas e 1 elaborada); acompanhamentos (arroz branco, arroz integral e feijão); duas guarnições (sendo 1 à base de vegetais); dois pratos proteicos (sendo 1 bovino); opção de prato proteico (vegetariano); seis tipos de sobremesa (4 frutas, 1 doce e 1 doce diet); três tipos de bebida (sendo 1 suco ou refresco e as outras, gaseificadas não alcoólicas).

A seleção de fornecedores era realizada pelo nutricionista, com o auxílio do setor de compras, de forma a atender à qualidade dos gêneros exigida pela contratante. A aquisição de materiais era realizada pelo setor de compras, que seguia as orientações do nutricionista offshore, com relação ao quantitativo e o tipo de material a ser adquirido.

O recebimento dos materiais perecíveis e estocáveis ocorria em áreas diferenciadas, protegidas e limpas, conforme recomendado pela RDC $\mathrm{n}^{\circ} 216 / 2004,{ }^{26}$ a fim de minimizar os riscos de contaminação cruzada e garantir a qualidade do produto final - neste caso, as refeições servidas aos trabalhadores das unidades de extração de petróleo.

Em qualquer tipo de serviço de alimentação, o controle da qualidade dos gêneros alimentícios deve ocorrer desde o recebimento da matéria-prima até o consumo das preparações, ${ }^{27}$ para manter a sanidade das refeições servidas. Nas empresas de hotelaria marítima, este controle deve ser ainda mais rigoroso, uma vez que possíveis surtos de doenças transmitidas por alimentos (DTA) podem causar sérios transtornos à população embarcada nas plataformas, devido a sua localização em alto mar, o que dificulta o acesso a serviços de emergência.

A fim de assegurar a qualidade dos gêneros alimentícios, durante o recebimento eram realizadas medidas de controle higiênico-sanitário, como: verificação da temperatura dos veículos; condições de entrega do fornecedor, da embalagem e o prazo de validade dos materiais (alimentares e não alimentares). Além disso, o controle quantitativo era realizado para evitar falhas na execução dos cardápios em etapas posteriores. Caso alguma não conformidade fosse observada durante o recebimento, solicitava-se ao fornecedor substituição e/ou devolução do material.

Para proceder ao armazenamento dos materiais, a empresa de hotelaria marítima contava com cinco câmaras frigoríficas, sendo três destinadas ao armazenamento de carnes bovina e suína, uma para laticínios e outra para hortifrutícolas. Havia três contêineres frigoríficos, sendo um para o armazenamento de sorvete e dois para aves e pescado; e ainda, contêineres específicos para estocagem de gêneros que não necessitavam de refrigeração, como produtos de limpeza e descartáveis. 
Verificou-se que a estrutura da área de armazenamento da base de apoio e logística do presente estudo era semelhante à descrita por Ghiurghi, ${ }^{5}$ com equipamentos diferenciados por tipo de material a ser acondicionado. Essa estrutura deve ser planejada de forma a apresentar dimensionamento e condições higiênico-sanitárias que atendam às necessidades quantitativas das unidades de alimentação e nutrição localizadas offshore e que garantam o acondicionamento dos materiais de rancho de forma segura. Desse modo, o armazenamento dos alimentos congelados era realizado em câmaras frigoríficas à temperatura de $-14^{\circ} \mathrm{C}$, sendo mantidas as embalagens secundárias originais (caixa de papelão); e os hortifrutícolas entre $5-10^{\circ} \mathrm{C}$. Os materiais (gêneros alimentícios, descartáveis e produtos de limpeza) que devem ser mantidos em temperatura ambiente eram armazenados em estoque seco, estando de acordo com a legislação sanitária vigente. ${ }^{26}$

A separação do material de rancho e demais materiais para a montagem do contêiner era realizada a partir da observação do mapa de requisição de materiais (pedido de rancho) elaborado e enviado pela nutricionista da plataforma. Nessa etapa, as embalagens secundárias dos alimentos eram retiradas, conforme recomendado na Resolução RDC n ${ }^{0} 72 / 2009,{ }^{25}$ que proíbe o armazenamento dos alimentos em embalagens de papel, papelão e outras de difícil higienização, e eram colocados em monoblocos, obedecendo a uma codificação por cores. Os produtos de limpeza eram colocados em monoblocos não vazados de cor marrom e os gêneros alimentícios em monoblocos vazados de cor branca. Em seguida, estes eram transferidos para seus respectivos contêineres (congelados, refrigerados e em temperatura ambiente).

A montagem dos contêineres obedecia à seguinte logística: contêineres elétricos para o transporte de alimentos congelados e refrigerados; contêineres $d r y$ (sem sistema de refrigeração) para alimentos que podiam ser mantidos à temperatura ambiente (produtos de limpeza $\mathrm{e}$ descartáveis). Os contêineres elétricos e dry eram de cor diferente para facilitar a identificação no embarque. Os contêineres de alimentos congelados eram organizados da seguinte forma: primeiro eram colocados os monoblocos de pescados, seguido das aves, carne bovina e por último o sorvete. O empilhamento dos monoblocos no contêiner devia ser feito de forma que sobrasse espaço para circulação interna de ar. Os monoblocos eram presos com uma rede de náilon resistente, a fim de minimizar o risco de desmoronamento durante o transporte, içamento e recebimento do mesmo na plataforma. Dentro do contêiner era colocado um equipamento para aferição/controle da temperatura, sendo a informação armazenada em chip, o que permitia observar a variação da temperatura durante o transporte do material de rancho alimentar.

Ao final da montagem, o contêiner era inspecionado pela nutricionista da empresa contratada, localizada onshore, e pelo fiscal de contrato designado pela contratante, sendo posteriormente lacrado. Os contêineres eram transportados por carretas até o Porto de Macaé-RJ, inspecionados e embarcados no rebocador/barco, rumo à plataforma. O horário e o local do abastecimento da embarcação eram comunicados com, no mínimo, duas horas de antecedência, à autoridade sanitária, conforme recomendado pela Resolução RDC no 72/2009. ${ }^{25}$ 
Considerando que as UANs localizadas nas plataformas ficam afastadas da costa e que o transporte do material de rancho pode durar cerca de 48 horas, dependendo da localização da plataforma em alto mar e das condições marítimas, o controle do tempo e temperatura dos contêineres é determinante para manter a qualidade dos gêneros alimentícios a serem entregues nas unidade de exploração de petróleo.

\section{Atividades desenvolvidas offshore}

As atividades de alimentação e nutrição realizadas offshore ocorriam nas unidades de exploração de petróleo (plataformas), onde havia o recebimento e armazenamento do material de rancho e outros materiais, produção e distribuição de refeições (figura 1).

Ao chegar à plataforma, os dados referentes à temperatura de transporte do material de rancho alimentar, que foram armazenados no chip, eram transferidos para um computador a fim de gerar relatórios, sendo possível avaliar a variação da temperatura durante o transporte e, caso os dados mostrassem permanência dos alimentos por longo período de tempo em temperatura de risco, o contêiner era devolvido imediatamente à base de apoio e logística. Esse procedimento poderia gerar alguns prejuízos, como aplicação de multa, perda de toda matéria-prima transportada e da confiança da qualidade dos serviços prestados pela empresa de hotelaria marítima. Além do exposto, a UAN localizada offshore não seria abastecida, o que poderia prejudicar a oferta de refeições aos trabalhadores embarcados.

O material de rancho obedecia a um cronograma semanal de recebimento e ao chegar à plataforma era inspecionado pelos profissionais enfermeiro e nutricionista. De acordo as Normas da Autoridade Marítima para Aquaviários (NORMAM) no1 13/2003, ${ }^{9} \mathrm{o}$ enfermeiro é o responsável por avaliar o recebimento do material de rancho a bordo, a fim de examinar sua qualidade e verificar se os alimentos apresentam riscos que possam prejudicar a saúde dos trabalhadores da unidade de extração de petróleo. Segundo essa Norma, também é atribuição do enfermeiro examinar, diariamente, os gêneros que saem dos paióis (estoques) e câmaras frigoríficas de bordo para o preparo das refeições.

Na empresa estudada, devido à existência de nutricionista no quadro de funcionários, essas atividades eram compartilhadas pelos profissionais de saúde a bordo. Vale ressaltar que, segundo a Resolução CFN n ${ }^{\circ}$ 380/2005, ${ }^{1}$ são atividades obrigatórias do nutricionista: o planejamento, a coordenação e a supervisão das atividades de seleção de fornecedores, procedência dos alimentos, bem como sua compra, recebimento e armazenamento de alimentos.

Durante a inspeção, os seguintes aspectos eram verificados: condições de higiene do contêiner, validade dos materiais e aspectos higiênico-sanitários dos gêneros alimentícios, ${ }^{28}$ visto que os 
alimentos a serem oferecidos devem ser obtidos de fontes aprovadas ou consideradas satisfatórias pelas autoridades competentes, com ausência de deterioração ou adulterações. ${ }^{25}$

Os primeiros gêneros a serem inspecionados eram as carnes, seguidos dos laticínios e os vegetais folhosos, uma vez que a forma de acondicionamento e o transporte demorado poderiam deteriorálos, tornando-os impróprios para consumo. Em seguida eram verificados aqueles armazenados sob temperatura ambiente. Após a inspeção, o material de rancho era prontamente descarregado, para ser devidamente armazenado. ${ }^{28}$

O nutricionista acompanhava o descarregamento e instruía a forma adequada de armazenamento a ser realizado pelo paioleiro. De acordo com a RDC $\mathrm{n}^{\mathrm{o}} 72 / 2005,{ }^{25}$ os materiais de rancho devem ser armazenados por tipo (sempre que possível) e sob temperatura adequada, a fim de preservar a qualidade higiênico-sanitária.

As áreas de armazenamento do material de rancho devem ser isentas de objetos estranhos ao ambiente, como equipamentos e utensílios em desuso, matéria-prima imprópria para consumo, produtos tóxicos ou outros que possam servir de fonte de contaminação dos alimentos ali estocados, conforme descrito na RDC $\mathrm{n}^{\circ} 72 / 2009 .{ }^{25}$ Vale ressaltar que esses mesmos cuidados devem ser adotados nos diferentes tipos de serviços de alimentação, independentemente de sua localização.

Para as atividades de pré-preparo, algumas UANs localizadas offshore contavam com área de carnes separada da área de vegetais e área de preparo equipada com forno, chapa bifeteira, fritadeira, fogão e outros equipamentos necessários à produção de refeições. Nas UANs em que não havia separação das áreas por meio físico, as etapas do processo produtivo eram realizadas em horários diferentes, para reduzir o risco de contaminação cruzada. Essas medidas eram adotadas em cumprimento a Resolução RDC $n^{\circ}$ 216/2004, ${ }^{26}$ que recomenda a separação entre as diferentes atividades por meios físicos ou outros meios, a fim de evitar a contaminação cruzada, manter a qualidade das refeições servidas e a saúde dos consumidores - neste caso, os trabalhadores das plataformas.

Nas 23 unidades de extração de petróleo, o número de trabalhadores variou de 40 a 377, e estes tinham direito a seis refeições diárias (desjejum, colação, almoço, lanche, jantar e ceia). Eram servidas, em média, 934 5527 refeições por dia.

Nas UANs localizadas nas plataformas, o desjejum era classificado como grande refeição, visto que as preparações oferecidas se assemelhavam àquelas servidas no almoço e jantar.

Em relação aos lanches, dependendo do tamanho da plataforma, em cada andar havia um ponto de distribuição, onde era oferecido: café, biscoito, iogurte e fruta, tanto no período matutino (colação), quanto no vespertino. Os gêneros ofertados nos pontos de lanche, assim como as quantidades, variavam conforme contrato firmado entre a contratante e a contratada. 
O sistema de distribuição das refeições era do tipo self-service, mas as UANs localizadas em plataformas internacionais (30\%) adotavam o sistema misto, com o porcionamento do prato principal.

Independentemente do sistema de distribuição, a manutenção da temperatura das preparações expostas ao consumo deve ser adequada e respeitada, minimizando assim o risco de multiplicação de microrganismos. Em estudo realizado por Alves \& Ueno, ${ }^{29}$ avaliando as condições sanitárias das preparações servidas nos restaurantes do tipo self-service, $15 \%$ das amostras das preparações quentes expostas ao consumo apresentavam temperatura abaixo de $40^{\circ} \mathrm{C}$ e $53,1 \%$ das amostras das preparações frias apresentavam temperatura superior a $21^{\circ} \mathrm{C}$. Os autores ainda relataram a contaminação por bactéria aeróbia mesófila, Staphylococcus coagulase positivo e coliformes, no rocambole de carne recheado com muçarela e no salpicão, que estavam expostos a $57,8^{\circ} \mathrm{C}$ e $28,3^{\circ} \mathrm{C}$, respectivamente. A relação entre as temperaturas medidas e a contaminação por microorganismos indicadores de qualidade sanitária reforça que a temperatura de distribuição das preparações tem papel relevante na segurança das refeições servidas.

Para garantir a qualidade das refeições servidas, deve ser realizado o controle do tempo e temperatura e mantido registro em formulário próprio, a ser apresentado à autoridade sanitária sempre que solicitado. ${ }^{25}$ As preparações que forem consumidas quentes devem ser mantidas à temperatura superior a $60^{\circ} \mathrm{C}$ por, no máximo, seis horas; e as preparações frias devem ser mantidas a $5^{\circ} \mathrm{C}$, a fim de manter sua qualidade higiênico-sanitária. ${ }^{25,26}$

O emprego inadequado da temperatura durante o processo produtivo de refeições, como a cocção insuficiente dos alimentos e a conservação das refeições sob temperatura de risco (10 a $60^{\circ} \mathrm{C}$ ) são fatores determinantes para a sobrevivência e multiplicação dos microorganismos, que podem resultar em ocorrência de surtos de DTA. ${ }^{30}$

Embora não tenham sido encontrados estudos que tratassem de surtos de DTA em UANs localizadas em plataformas, há relatos desta síndrome em navios de cruzeiro (que também apresentam confinamento por outro objetivo, o lazer). Rooney et al. ${ }^{31}$ estudaram os surtos de DTA que acometeram os passageiros de cruzeiros entre os anos de 1970 e 2003, e relataram a presença dos seguintes microrganismos: Salmonella spp., Escherichia coli, Shigella spp., Vibrio spp., Staphylococcus aureus e Clostridium perfringens. Passos et al. ${ }^{32}$ relataram a ocorrência de distúrbios gastrointestinais (vômitos, dores abdominais, cefaleia) em passageiros de navio destinado a cruzeiros.

Com relação aos resíduos orgânicos alimentares gerados pela UAN localizadas offshore, estes eram acondicionados em reservatório próprio (lixeira orgânica), para posteriormente serem triturados e descartados em alto mar. Os resíduos sólidos recicláveis eram acondicionados em bags de lixo ou caçambas, e a empresa contratante era responsável pela destinação final dos mesmos. 
Assim como nas embarcações de turismo, o processo produtivo de refeições realizado nas empresas de hotelaria marítima precisa de cuidado redobrado, pois acontece em dois momentos distintos (onshore e offshore), o que aumenta o risco de contaminação dos alimentos.

Estes resultados reforçam a necessidade do controle adequado do processo de produção de refeições realizado nas UANs localizadas offshore, de modo a inviabilizar o crescimento, multiplicação e disseminação de microrganismos patogênicos e manter a saúde dos trabalhadores que desenvolvem suas atividades embarcados em unidades de extração de petróleo.

\section{Conclusão}

Embora o processo produtivo de refeições seja semelhante ao conduzido por diversas UANs, a maior complexidade observada na hotelaria marítima se dá em função de as atividades acontecerem em dois espaços distintos (onshore e offshore), sendo necessário um controle rigoroso da quantidade e qualidade de material de rancho a ser utilizado.

O controle da qualidade dos materiais de rancho deve ser realizado ao longo de todo o processo produtivo de refeições. O monitoramento da temperatura dos contêineres contendo o material de rancho alimentar deve ser rigoroso, uma vez que seu transporte até a plataforma pode ocorrer durante um longo período de tempo e falhas nesse processo podem acarretar em custos adicionais, inclusive multas para a empresa de serviço de alimentação contratada.

O nutricionista possui papel fundamental na manutenção da qualidade das refeições produzidas e do bem-estar e saúde dos trabalhadores, que permanecem por longo tempo embarcados em ambiente confinado.

Embora a atuação do nutricionista no segmento de hotelaria marítima venha crescendo ao longo dos últimos anos, poucos estudos têm sido realizados. Logo, pesquisas acerca da atuação dos nutricionistas em unidades de alimentação e nutrição localizadas offshore devem ser conduzidas, a fim de promover possíveis melhorias e dar visibilidade à atuação desses profissionais.

\section{Referências}

1. Resolução $\mathrm{CFN} \mathrm{N}^{\circ} 380$. Dispõe sobre a definição das áreas de atuação do nutricionista e suas atribuições, estabelece parâmetros numéricos de referência, por área de atuação, e dá outras providências. 28 dez. 2005.

2. Davies CA. Manual de hospedagem: simplificando ações na hotelaria. 3. ed. EDUCS; 2002. 233 p. 
3. Mello G, Goldenstein M. Perspectivas da hotelaria no Brasil. BNDES Setorial 2011; 33:5-42. Disponível em: http://www.bndes.gov.br/SiteBNDES/export/sites/default/bndes_pt/Galerias/ Arquivos/conhecimento/bnset/set3301.pdf.

4. Teixeira AA. A exploração e produção de petróleo no Brasil: 15 anos de abertura. Interesse nacional. Interesse Nacional [Internet] 2013; (22). Disponível em: http://interessenacional.uol.com.br/index. php/edicoes-revista/a-exploracao-e-producao-de-petroleo-no-brasil-15-anos-de-abertura/3/

5. Ghiurghi F. LC tem novo centro de distribuição em Macaé, RJ. Food and News [Internet] 20 out. 2014. Disponível em: http://foodandnews.com/busca/tags $\% 3 \mathrm{~A}+$ mais +qualidade +qual/5957-LC +TEM+NOVO+CENTRO+DE+DISTRIBUI $\%$ C3\% $\% 7 \%$ C3\%83O+EM+MACA $\%$ C3\% $\% 9$,+RJ

6. Freitas CM, Souza CAV, Machado JMH, Porto MFS. Acidentes de trabalho em plataformas de petróleo da Bacia de Campos, Rio de Janeiro. Cad. Saúde Pública 2001; 17(1):117-130.

7. Guedes CCP, Aguiar BGC. Discutindo e refletindo sobre a competência do enfermeiro offshore. Rev. Enferm. UERJ 2012; 20(1):61-6.

8. Corrêa DDC, Andrade M, Coimbra L. Espaço líquido: o enfermeiro como agente do cuidado no ambiente offshore. Rev. Enferm UFPE 2013; 7(12):6907-12.

9. Marinha do Brasil. Normas da Autoridade Marítima para Aquaviários (NORMAM 13-DPC). Estabelecer normas de procedimentos relativos ao ingresso, inscrição e à carreira dos aquaviários pertencentes aos $1^{\circ}, 2^{\circ}, 3^{\circ}, 4^{\circ}, 5^{\circ}$ e $6^{\circ}$ Grupos e para concessão e emissão de Certidão de Serviços de Guerra. 2003.

10. Gil A. Métodos e técnicas de pesquisa social. São Paulo: Atlas; 1999.

11. Alvarez MEB. Organização, sistemas e métodos. São Paulo: McGraw Hill; 1991.

12. Triviños ANS. Introdução à pesquisa em ciências sociais. São Paulo: Atlas; 1987.

13. Minayo MCS. O desafio do conhecimento: pesquisa qualitativa em saúde. 5. ed. São Paulo: Hucitec; Rio de Janeiro: ABRASCO; 1998.

14. Pessanha RM. O trabalho offshore: inovação tecnológica, organização do trabalho e qualificação do operador de produção na Bacia de Campos, RJ [dissertação]. Rio de Janeiro: Universidade Federal do Rio de Janeiro; 1994.

15. Maia Neto L. Identificação de perigos e avaliação de riscos em uma unidade offshore de na fase de operação: estudo de caso de um FPSO [dissertação]. Niterói (RJ): Universidade Federal Fluminense; 2007.

16. Leite RMSC. O Trabalho nas plataformas marítimas de petróleo na bacia de Campos: a identidade do trabalhador offshore [tese]. Rio de Janeiro: Universidade Federal do Rio de Janeiro. Programa de Pós-Graduação em Serviço Social; 2006.

17. Brasil. Lei no 5811, de 11 de outubro de 1972. Dispõe sobre o regime de trabalho dos empregados nas atividades de exploração, perfuração, produção e refinação de petróleo, industrialização do xisto, indústria petroquímica e transporte de petróleo e seus derivados por meio de dutos. Diário Oficial da União 11 out. 1972.

18. Freitas CM, Souza CAV, Machado JMH, Porto MFS. Acidentes de trabalho na plataforma de petróleo da Bacia de Campos do Rio de Janeiro, Brasil. Cad. Saúde Pública 2001; 17(1):117-130. 
19. Guedes CCP, Aguiar BGC, Tonini T. Características do ambiente de trabalho do enfermeiro em plataforma de petróleo offshore. Rev. Enferm. UERJ 2011; 19(4):657-62.

20. Nielsen MB, Eid J, Hystad SW, Sætrevik B, Saus ER. A brief safety climate inventory for petromaritime organizations. Safety Science 2013, 58:81-88.

21. Colares LGT, Freitas CM. Processo de trabalho e saúde de trabalhadores de uma unidade de alimentação e nutrição: entre a prescrição e o real do trabalho. Cad. Saúde Pública 2007; 23(12):3011-3020.

22. Rodrigues VF. Relações de trabalho em Unidades de Perfuração Marítima: estudo de caso com ênfase em trabalho em turnos [tese]. Alfenas, MG: Universidade José do Rosário Vellano, Programa de Pós-Graduação em Administração; 2000.

23. Castro AC, Nunes DKP. Análise crítica do gerenciamento de stress em plataformas marítimas. Anais do XXVIII Encontro Nacional de Engenharia de Produção. Rio de Janeiro; 2008.

24. Coelho LLV, Paparelli R. A experiência do trabalhador offshore: o caso de operadores de ROV. Seminário de Saúde do Trabalhador de Franca 2010.

25. Brasil. Resolução da Diretoria Colegiada No 72/2009, de 29 dezembro de 2009. Dispõe sobre o Regulamento Técnico que visa à promoção da saúde nos portos de controle sanitário instalados em território nacional, e embarcações que por eles transitem.

26. Brasil. Resolução da Diretoria Colegiada n ${ }^{\circ}$ 216, de 15 de setembro de 2004. Dispõe sobre Regulamento Técnico de Boas Práticas para Serviço de Alimentação.

27. Panza SGA, Silva CR. Avaliação das condições de transporte e recebimento de carne bovina resfriada, em supermercados de grande porte na cidade de Maringá, PR. Higiene Alimentar 2007; 21(153):46-52.

28. Amorim GH, Guedes MAS, Guedes CCP, Aguiar BGC. Enfermeiro embarcado em plataforma petrolífera: um relato de experiência offshore. Texto \& Contexto Enferm. 2013; 22(1):257-265.

29. Alves MG, Ueno M. Restaurantes self-service: segurança e qualidade sanitária dos alimentos. Rev. Nutr. 2010; 23(4):573-80.

30. Silva Jr. EA. Manual de controle higiênico-sanitário em serviço de alimentação. São Paulo: Varela; 2005.

31. Rooney RM, Cramer EH, Mantha S, Nichols G, Bartram JK, Farber JM et al. A review of outbreaks of foodborne disease associated with passenger ships: evidence for risk management. Public Health Rep. 2004; 119:427-34.

32. Passos EC, Mello ARP, Sousa CV, Alonso ACB, Gonzalez E, Tavares M. Avaliação microbiológica da alimentação servida aos passageiros de um navio de cruzeiro na temporada 2009/2010. Detecção de Bacillus cereus em refeição à base de peixe. Rev. Inst. Adolfo Lutz 2010; 69(4):571-5.

33. Sindicato dos Nutricionistas do Estado do Rio de Janeiro. 2015. Acordos coletivos. [acesso em: 18 ago. 2015]. Disponível em: http://www.sinerj.org.br/

Recebido: 07/1/2015

Revisado: 17/2/2016

Aceito: 18/3/2016 
